\title{
Online Loss Parameters Diagnosis Device Development of Power Cable Insulation
}

\author{
Jie Chen, Chenying Li, Libin Hu, Jingying Cao, Xiao Tan \\ State Grid Jiangsu Electric Power Research Institute, Nanjing, China \\ Email:2008840320@163.com
}

How to cite this paper: Chen, J., Li, C.Y., Hu, L.B., Cao, J.Y. and Tan, X. (2017) Online Loss Parameters Diagnosis Device Development of Power Cable Insulation. Energy and Power Engineering, 9, 216-223. https://doi.org/10.4236/epe.2017.94B026

Received: February 24, 2017

Accepted: March 30, 2017

Published: April 6, 2017

\begin{abstract}
In southern China, power cable lines often running in water, and the state of XLPE insulation is difficult to detection effectively. This paper studied loss parameters online diagnosis technology of power cable insulation. An online loss parameters diagnosis device was development, which consists of current comparator, voltage controlled current source (VCCS), standard capacitor, GPRS wireless transmission system, control system and the data processing unit. 108 cables were detected using this device, and it was found out that one cable appeared to middle aging and eight cables appeared to slight aging. The butterfly water trees were observed in middle aging cable, which prove the effectiveness of online testing in the loss current measurement.
\end{abstract}

\section{Keywords}

Loss Parameters, Power Cable Insulation, Onlinetesting, Aging

\section{Introduction}

Owing to its large transmission capacity, good insulation performance and easy maintenance, cross-linked polyethylene (XLPE) power cables are increasingly utilized in urban transmission lines. So, the reliable running of XLPE power cables is becoming more important. However, when suffered a long-term alternating electric field and humidity, the chemical component and micro structure of cable insulation material may be changed, and finally lead to the irreversible degradation, which is called water tree aging.

The method of water tree diagnosis which consists of dielectric loss detection is essential to insure the safety of power cables. Due to different frequency of applied voltage, the dielectric loss detection could be divided into $0.1 \mathrm{~Hz}, 50 \mathrm{~Hz}$ and varied frequency [1] [2] [3] [4]. However, power cables are offline during this measurement process. To solve this problem, a dielectric loss detection device was developed to meet the XLPE cable online testing needs in this paper. 


\section{Theoretical Analysis}

\subsection{Loss Current Harmonic Component Testing Principle}

The relationships among loss current, capacitance current and total current are shown in Figure 1. During equivalent circuit of cable insulation structure, loss current and capacitance current are parallel and vertical to applied voltage respectively [5] [6].

The aging degree of cable insulation could be effectively revealed by its loss current harmonic component which is illustrated from previous research. Due to water and low molecular degradation products, equivalent impedance of insulation material is nonlinear when XLPE cable is water treed. After AC voltage applied, the harmonic components of loss current are detected. Thus, the method of loss current harmonic component measurement could be used to diagnose water tree aging degree in XLPE cable insulation.

\subsection{On-Site Testing Principle}

The diagram of loss parameters online diagnose device was shown in Figure 2, which consists of current comparator, voltage controlled current source (VCCS), standard capacitor, GPRS wireless transmission system, control system and data processing unit.

The relationships among start point current, end point current and leakage current $I$ are shown in Figure 3. It could be concluded that loss current may be acquired by Equation (1).

$$
\dot{I}_{\text {loss }}=\dot{I}-\dot{I}_{c}=\dot{I}_{1}-\dot{I}_{2}-\dot{I}_{c}
$$

$I_{1}$ was start point current

$I_{2}$ was end point current

These two current could be measured by current comparators in start and end point [7] [8].

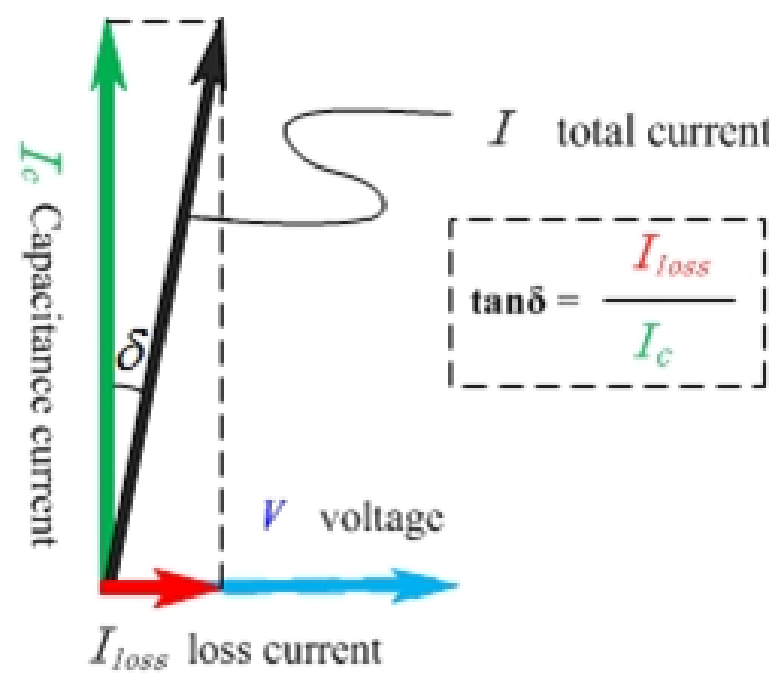

Figure 1. Relationships among loss current, capacitance current, total current and applied voltage. 


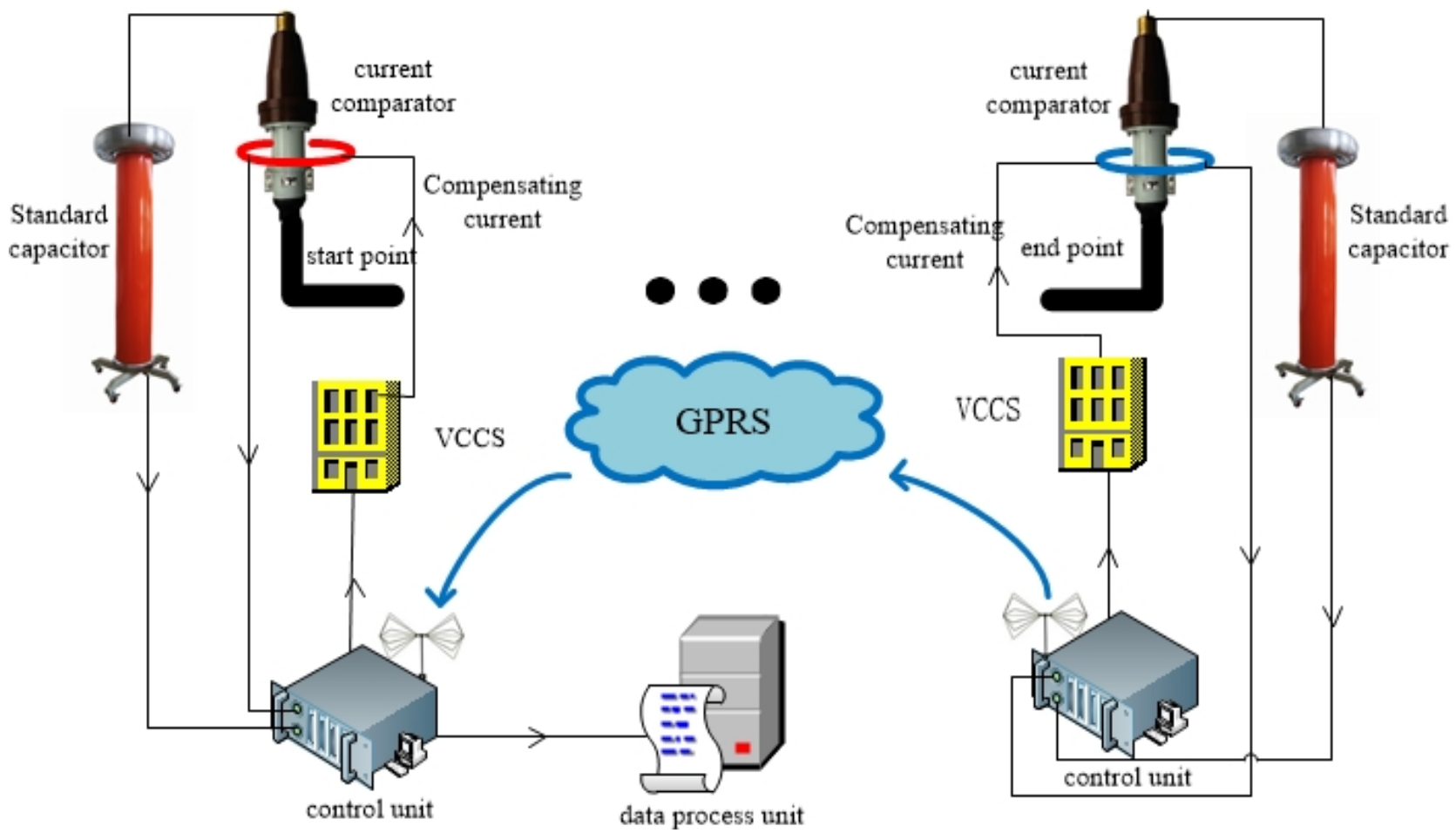

Figure 2. Diagram of loss parameters online diagnose device.

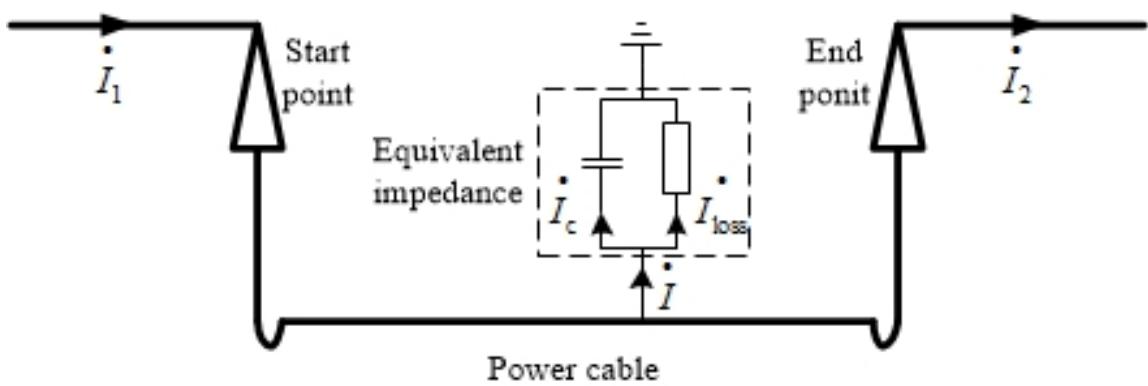

Figure 3. Relationships among different current.

A real-time voltage could be measured by standard capacitor located at start and end point. So, lossfactor and loss current harmonic components could be obtained by vector arithmetic of the leakage current and real-time voltage. During the process, current comparators were compensated by precision VCCS which controlled by real-time process software.

\section{Device Development}

\subsection{Theoretical Analysis of Current Measurement}

The diagram of current dynamic compensation and measurement was shown in Figure 4, which consists of current comparator, VCCS and controlunit.

Firstly, when high voltage applied to power cable, the detection coil ND of current comparator would detect unbalanced signal $u_{2}(t)$ due to magnetic potential generated by core. Secondly, control unit would output compensation signal to VCCS by the least squares algorithm of excitation voltage signal $u_{1}(t)$ and 


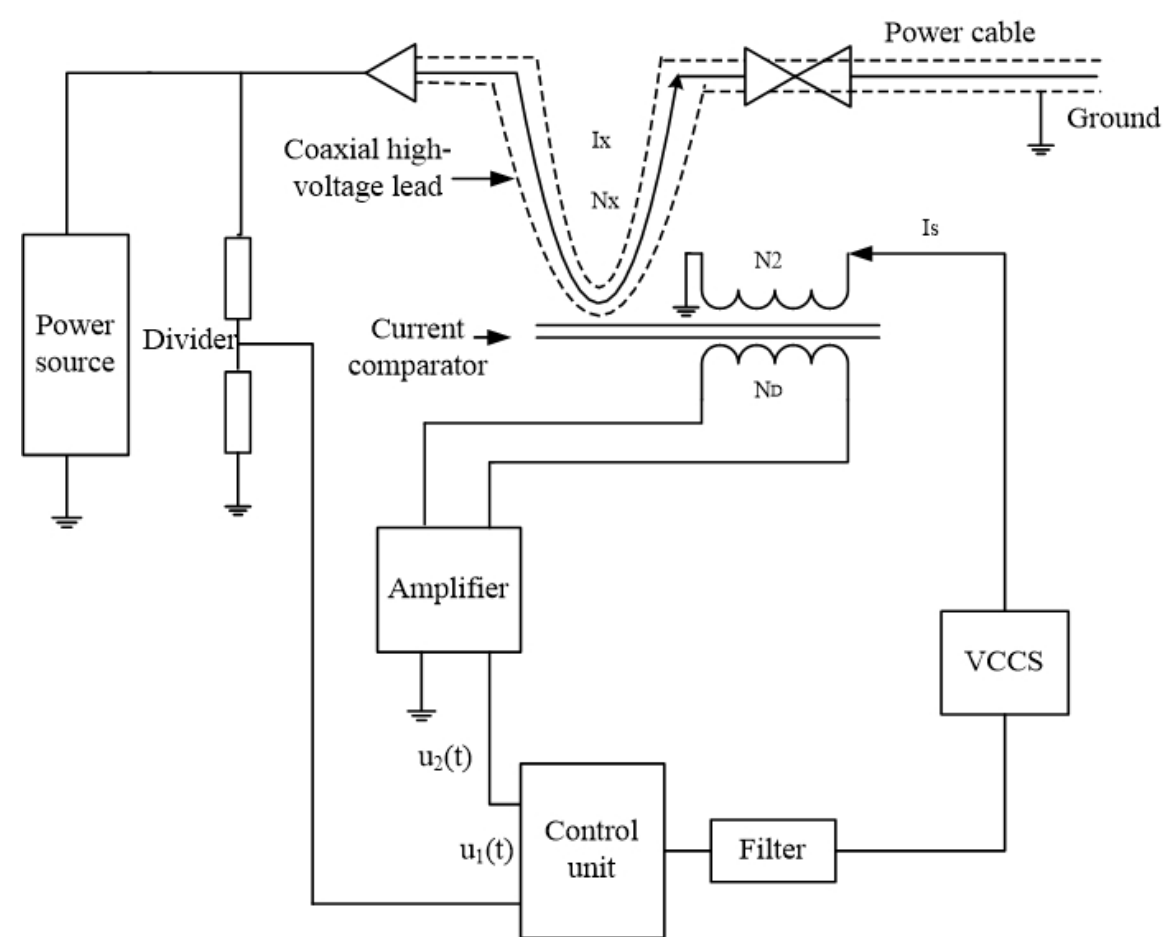

Figure 4. Currentdynamic compensation and measurement.

unbalanced signal $u_{2}(t)$. Thirdly, the VCCS output compensation current to comparator coil of current comparator and produced an inverting magnetic potential, contrasting with magnetic core of current comparator. Finally, current comparator automatic compensation with zero output current ultimately.

\subsection{Current Comparator}

Current comparator was widely used for measurement and calibration of dielectric loss factor $\tan \delta$ of high voltage equipment. In this paper, structure of current comparator was shown in Figure 5. It was apparent that the main parts include Permalloy toroid core, detection coil $N_{D}$ copper screen, adjust the coil $N_{A}$, coarse coils $N_{2}$, trim coil $N_{1}$, magnetic shielding and cable coil $N_{X}$.

The sensitivity of current comparator was proportional to permeability of Permalloy toroid core and density of detection coil $N_{D^{*}}$ The Permalloy toroid core had a high permeability and the detection coil $N_{D}$ was wound with a high density onto the core to ensure maximum sensitivity. To eliminate interference, two copper screens and a magnetic shield were used to screen detection coil. The picture of current comparator was shown in Figure 6.

\subsection{Voltage Controlled Current Source}

AVCCS with 50 A output peak current was developed in this paper, and applied to the current comparator to achieve high-speed dynamic compensation during the current measurement process. The VCCS was divided into coarse and fine tuning units. The VCCS test range was decided by coarse-tuneunit connected to $N_{2}$ coil, while the accuracy of VCCS was determined by fine-tune unit connected 


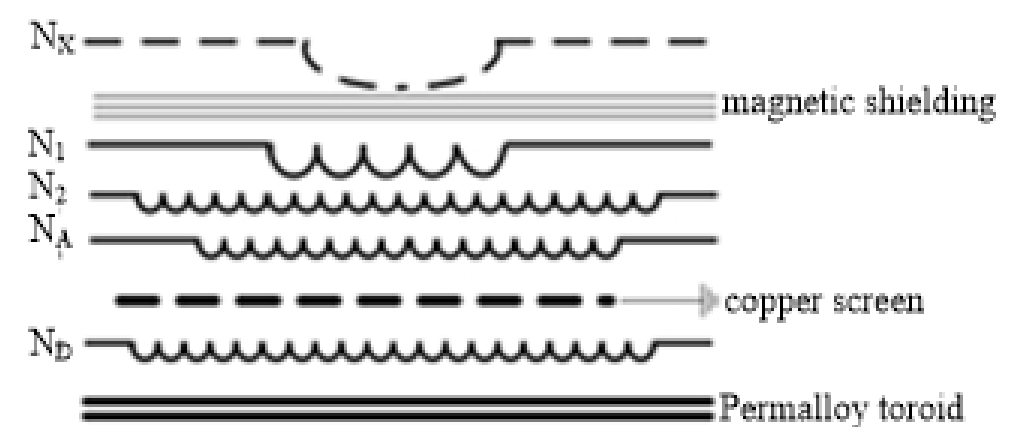

Figure 5. Structure of current comparator.

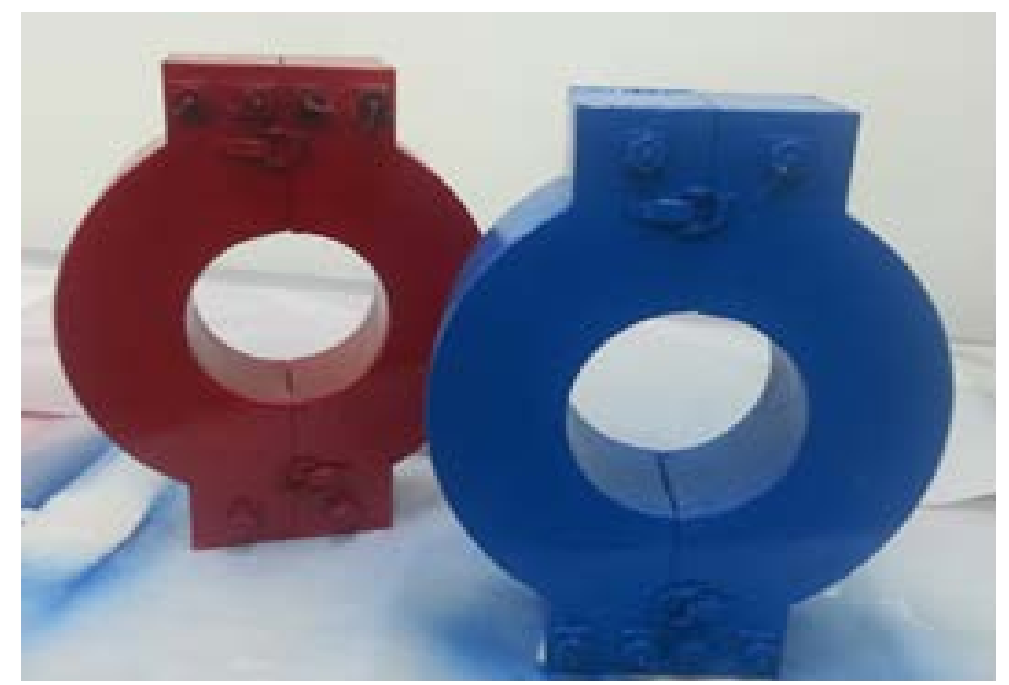

Figure 6. Picture of online current comparator.

to $N_{1}$ coil.

Influence of loads on VCCS output characteristics was studied in this paper. It was found out that coarse-tuneunit was not distortion in the output current of $60 \mathrm{~A}$, which meet the $50 \mathrm{~A}$ measurement range requirements in actual engineering. Moreover, fine-tune unit was not distortion with $4.5 \mathrm{k} \Omega$ load resistance which meet the requirements of accuracy requirements.

\subsection{Standard Capacitor Voltage Measurement}

The AC voltage measuring system was made of high voltage standard capacitor, protective circuit and signal processing circuit, which was shown in Figure 7.

The standard capacitor would change high voltage signal into capacitive current signal $I_{\mathrm{C}}$, as shown in Equation (2):

$$
\begin{gathered}
I_{C}(t)=C_{H} \frac{d u_{p}(t)}{d t} \\
u_{q}=-\frac{1}{C_{J}} \int I_{C}(t) d t=-\frac{C_{H}}{C_{J}} u_{p}(t)
\end{gathered}
$$

$C_{J}$ was an integral capacitor.

The output signal could be obtained by Equation (4): 


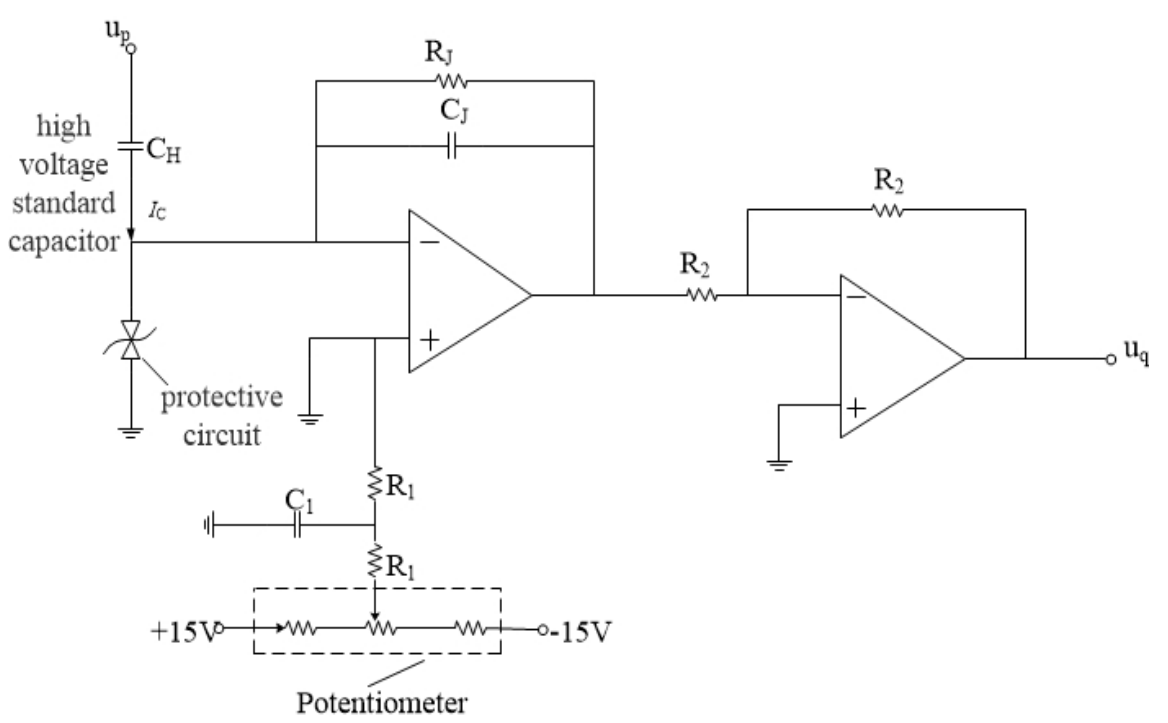

Figure 7. Diagram of high-voltage measuring system.

$$
\frac{u_{q}}{u_{p}}=-\frac{C_{H}}{C_{J}}
$$

Due to the temperature coefficient of high voltage standard capacitor was nearly zero, the effect of temperature variation on current voltage conversion circuit was only analyzed in this paper. The resistor or capacitor parameters of the current voltage conversion circuit relate to temperature, so the temperature will be smaller impact on the AC high-voltage measuring system, and the above temperature error could be further reduced by selecting resistor or capacitor with low and equivalent temperature coefficient.

\section{Experimental Study}

For a long time, dielectric loss factor has been used to determine the important parameters of cross-linked polyethylene cable insulation aging state, and has become widely accepted criterion, which was shown in Table 1.

Moreover, loss current harmonic ratio is defined as the amplitude of the loss current third harmonic vs. the amplitude of the loss fundamental current in this paper. In order to eliminate the effect of cable length and other factors, loss current harmonic ratio was used to determine water tree aging classification judgment criterion, which was shown in Table 2.

$108,20 \mathrm{kV}$ cables were evaluated using loss parameters online diagnose device produced in this paper. It was found out that one cable appeared to middle aging and eight cables appeared to slightly aging, with the test results were shown in Table 3.

All the 8 cables with slight water tree aging passed the withstand voltage tests later, meanwhile the cable with middle aging didn't pass. The breakdown cable was sliced and observed by optical microscope to observe water trees, which was shown in Figure 8. 
Table 1. XLPE insulation aging vs. dielectric loss factor.

\begin{tabular}{ccc}
\hline Testing result & Aging state & Next detection time \\
\hline $\tan \delta \leq 1.2 \times 10^{-3}$ & No aging & 5 years later \\
$1.2 \times 10^{-3} \leq \tan \delta \leq 2.2 \times 10^{-3}$ & Slightly aging & 1 year later \\
$2.2 \times 10^{-3} \leq \tan \delta$ & Severly aging & Normally \\
\hline
\end{tabular}

Table 2. XLPE insulation aging vs. dielectric loss current harmonic ratio.

\begin{tabular}{ccc}
\hline Ratio testing result & Aging state & Next detection time \\
\hline$(0,0.05)$ & No aging & 5 years later \\
$(0.05,0.15)$ & Slightly aging & 2 year later \\
$(0.15,0.5)$ & middle aging & 2 year later \\
$>0.5$ & Severly aging & Normally \\
\hline
\end{tabular}

Table 3. Testing result with loss factor and loss current harmonic ratio.

\begin{tabular}{|c|c|c|c|c|c|c|c|c|}
\hline \multirow[b]{2}{*}{ NO. } & \multirow{2}{*}{$\begin{array}{l}\text { Volt } \\
(\mathrm{kV})\end{array}$} & \multicolumn{2}{|c|}{$\mathrm{A}$} & \multicolumn{2}{|c|}{ B } & \multicolumn{2}{|c|}{ C } & \multirow[t]{2}{*}{ Conclusion } \\
\hline & & $\begin{array}{c}\operatorname{Tan} \delta \\
\left(\times 10^{-4}\right)\end{array}$ & Ratio & $\begin{array}{c}\operatorname{Tan} \delta \\
\left(\times 10^{-4}\right)\end{array}$ & Ratio & $\begin{array}{c}\operatorname{Tan} \delta \\
\left(\times 10^{-4}\right)\end{array}$ & Ratio & \\
\hline \multirow{2}{*}{15} & 6 & 5.37 & 0.205 & - & - & - & - & \multirow{2}{*}{ A middle aging } \\
\hline & 8 & 5.46 & 0.227 & - & - & - & - & \\
\hline \multirow{2}{*}{27} & 6 & 3.36 & 0.089 & 3.76 & 0.095 & 3.83 & 0.071 & \multirow{2}{*}{$\mathrm{ABC}$ slightly aging } \\
\hline & 8 & 3.46 & 0.082 & 3.70 & 0.090 & 3.49 & 0.066 & \\
\hline \multirow{2}{*}{28} & 6 & 4.13 & 0.152 & 4.12 & 0.102 & 4.99 & 0.133 & \multirow{2}{*}{$\mathrm{ABC}$ slightly aging } \\
\hline & 8 & 3.76 & 0.141 & 3.89 & 0.092 & 4.79 & 0.113 & \\
\hline \multirow{2}{*}{34} & 6 & - & - & 3.66 & 0.075 & 3.63 & 0.051 & \multirow{2}{*}{ BC slightly aging } \\
\hline & 8 & - & - & 3.74 & 0.104 & 3.77 & 0.049 & \\
\hline
\end{tabular}

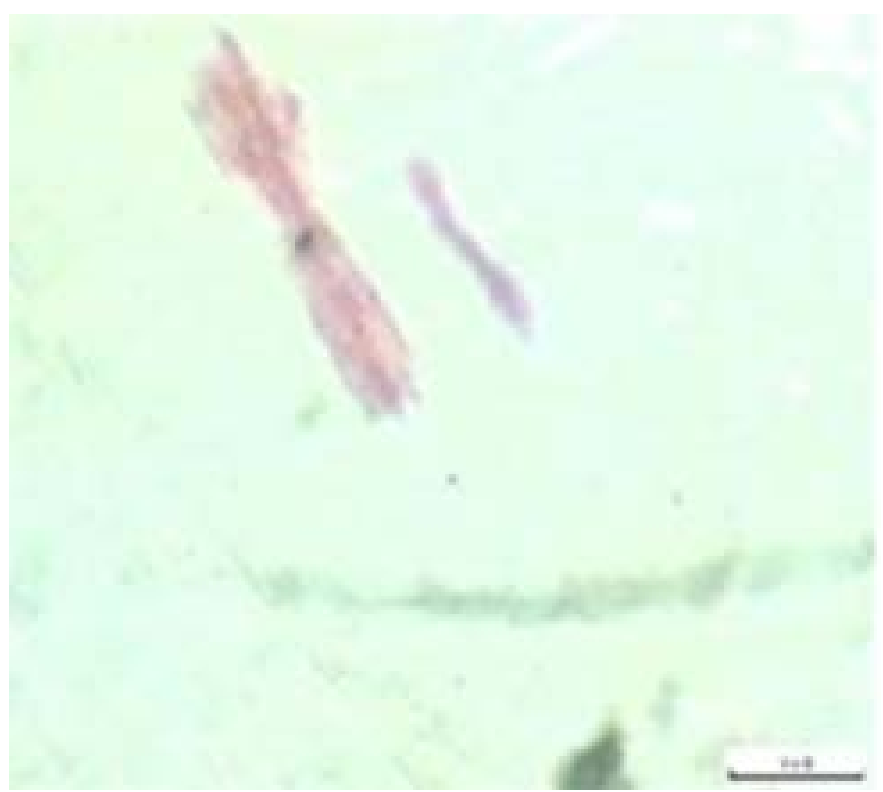

Figure 8. Optical microscope observation of water trees in the withstand voltage breakdown cables. 


\section{Conclusion}

This paper studied loss parameters online diagnosis technology of power cable insulation. An online loss parameters diagnosis device was development, which consists of current comparator, voltage controlled current source (VCCS), standard capacitor, GPRS wireless transmission system, control system and the data processing unit. 108 cables were detected using this device, and it was found out that one cable appeared to middle aging and eight cables appeared to slightly aging. The butterfly water trees were observed in middle aging cable, which prove the effectiveness of online testing in the loss current measurement.

\section{References}

[1] Faifer, M., Toscani, S., Ottoboni, R. (2011) Electronic Combined Transformer for Power-Quality Measurements in High-Voltage Systems. IEEE Transactions on Instrumentation \& Measurement.

[2] Kosakada, M., Watanabe, H., Ito, T., et al. (2002) Integrated Substation SystemsHarmonizing Primary Equipment with Control and Protection Systems. Transmission and Distribution Conference and Exhibition Asia Pacific. IEEE/PESIEEE, 2, 1020-1025.

[3] Hirotsu, K. (1994) Development of Hot-Line Diagnosis Method for XLPE Cables by Measurement of Harmonics Current. Proceedings of 1994 International Joint Conference: 26th Symposium on Electrical Insulation Materials, Osaka, 455-458.

[4] Moreau, E., Mayoux, C. and Laurent, C. (1993) The Structure Characteristics of Water Trees in Power Cables and Laboratory Specimens. IEEE Trans. on EI, 1, 5464.

[5] Shen, B.H. (2010) Investigation of Localized Production of HV Insulation Compound. Electric Wire and Cable, 1.

[6] Wei, X.L., Zhu, B., Pang, B., Wang, S. and Li, R.H. (2015) On-Line Insulation Monitoring Method for Long Distance Three-Phase Power Cable. Proceedings of the Chinese Electrical Engineering Science, 35.

[7] Yagi, Y., Tanaka, H. and Kimura, H. (1998) Study on Diagnostic Method for XLPE Cable by Harmonicsin Loss Current. Electrical Insulation and Dielectric Phenomena, 653-656.

[8] Tanaka, A., Yagi, Y. and Tanaka, H. (2003) On-Site Diagnostic Method for Water Treed XLPE Cable by Harmonics in AC Loss Current. Electrical Insulation NewNews in Asia, 10, 29-30. 
Submit or recommend next manuscript to SCIRP and we will provide best service for you:

Accepting pre-submission inquiries through Email, Facebook, LinkedIn, Twitter, etc. A wide selection of journals (inclusive of 9 subjects, more than 200 journals)

Providing 24-hour high-quality service

User-friendly online submission system

Fair and swift peer-review system

Efficient typesetting and proofreading procedure

Display of the result of downloads and visits, as well as the number of cited articles Maximum dissemination of your research work

Submit your manuscript at: http://papersubmission.scirp.org/

Or contact epe@scirp.org 